\title{
VIBRO-THERMOGRAPHY OF DEBONDING DEFECTS IN COMPOSITE PLATES
}

\author{
Liang Zhu, Xingwang Guo \\ Beihang University, 37 Xue Yuan Rd. Haidian District, Beijing 100191,China
}

\begin{abstract}
Vibrothermography has better capability of detecting kissing defects than other infrared thermal approaches. The ultrasonic excitation frequency is an important parameter except the power in vibrothermography. The vibrothermography of debonding defects in composite plates are researched in this paper. The ultrasonic waves ranging from $17 \mathrm{kHz}$ to $32 \mathrm{kHz}$ are used separately as the excitation source to pump energy into the composite plate. The experimental result shows that all of the 8 premade debonding defects are well detected under the excitation frequency around $21.5 \mathrm{kHz}$, whereas only a part of or no defect is detected under other excitation frequencies. To explain this experimental result, the natural frequencies of the plate under a series of boundary conditions and the local resonance frequency of the defect areas were calculated. A numerical simulation model is established to study the quantitative relationship between the excitation frequency and the temperature increase of the defect areas, and the analysis of the coupled physical field between vibration and heat conduction are employed to reveal the relationship between the excitation frequency and the natural frequency of the whole plate and/or the local defect areas for the optimum testing.
\end{abstract}

KEYWORDS: Vibrothermography, Composite plate, Debonding, Local defect resonance

\section{INTRODUCTION}

Vibrothermography is one of the infrared thermal non-destructive testing. It has been paid more attention in recent years due to its high efficiency, good repeatability and capability of detecting kiss defects. The principle of vibrothermography and the factors that govern the mechanical energy turning into heat during vibration are researched from different views by many teams all over the world [1]. The most recently development about vibrothermography is the local resonance theory [2][3], however, the specimen with only one artificial defect can't illustrate the case for complex multi-defect structures. The vibrothermography of a composite plate with multiple debonding defects will be researched in this paper.

\section{THEORETICAL ANALYSIS}

\subsection{Detection principle}

When an elastic wave propagates in solid media containing defects, the discontinuity of media may lead to its serious attenuation. The friction between discontinued faces or the viscoelastic effect of the defective areas may lead to heat generation and temperature changes which can be detected by infrared cameras.

\subsection{Vibration theory}

Two composite plates consisting of aluminum alloy and cork layers were used as the reference samples. The analysis of vibration modes is based on the classical vibration theory of plates. The motion for the transverse displacement $w$ of a plate is given by [4]:

$$
D \nabla^{4} w+\rho \frac{\partial^{2} w}{\partial t^{2}}=0
$$

where $\rho$ is the density, $h$ is the thickness of the plate, $D$ is the flexural rigidity defined by 


$$
D=\frac{E h^{3}}{12\left(1-\mu^{2}\right)}
$$

where $E$ is Young's modulus, $\mu$ is Poisson's ratio.

The frequency equation of a rectangle plate under different boundaries can be given as Eq.(2):

$$
\omega^{2}=\frac{\pi^{4} D}{a^{4} \rho}\left\{G_{x}^{4}+G_{y}^{4}\left(\frac{a}{b}\right)^{4}+2\left(\frac{a}{b}\right)^{2}\left[\mu H_{x} H_{y}+(1-\mu) J_{x} J_{y}\right]\right\}
$$

where $\omega$ denotes the angular frequency, $a$ and $b$ represent the length dimension and the width dimension of the plate respectively, coefficients $G_{x}, G_{y}, H_{x}, H_{y}, J_{x}$ and $J_{y}$ depend on the boundary conditions. The most common three boundary conditions are as shown in Table 1[4].

\begin{tabular}{|c|c|c|c|c|c|c|c|}
\hline Boundary conditions & Order & $G_{x}$ & $G_{y}$ & $H_{x}$ & $H_{y}$ & $J_{x}$ & $J_{y}$ \\
\hline \multirow{3}{*}{ स्र्र } & $1^{\text {st }}$ & 1.506 & 1.506 & 1.248 & 1.248 & 1.248 & 1.248 \\
\hline & $2^{\text {nd }}$ & 2.5 & 1.506 & 4.6585 & 1.248 & 4.6585 & 1.248 \\
\hline & $3^{\text {th }}$ & 3.5 & 1.506 & 10.0218 & 1.248 & 10.0218 & 1.248 \\
\hline \multirow{6}{*}{ 矛 } & $1^{\text {st }}$ & 0.597 & 0 & -0.087 & 0 & 0.471 & 0 \\
\hline & $2^{\text {nd }}$ & 0.597 & 0 & -0.087 & 0 & 0.471 & $12 / \pi^{2}$ \\
\hline & $3^{\text {th }}$ & 1.494 & 0 & 1.347 & 0 & 3.284 & 0 \\
\hline & $1^{\text {st }}$ & 1 & 1 & 1 & 1 & 1 & 1 \\
\hline & $2^{\text {nd }}$ & 2 & 1 & 4 & 1 & 4 & 1 \\
\hline & $3^{\text {th }}$ & 3 & 1 & 9 & 1 & 9 & 1 \\
\hline
\end{tabular}

Table1. Three boundary conditions and the coefficients for the first three order frequencies of a rectangle plate

Because the artificial defect is cylindrical shape, for the calculation of local resonance frequency of defected area should be based on the vibration of the circular plate, as for a circular thin plate, the resonance frequency equation in flexural vibration can be defined by:

$$
\omega=\frac{\lambda^{2}(n)}{R^{2}} \sqrt{\frac{E h^{3}}{12 \rho\left(1-\mu^{2}\right)}}
$$

$n$ represents the order of angular frequency, $R$ is radius of the plate, $\lambda^{2}(n)$ is different for different boundary conditions and orders.

Table.2 Coefficients for the frequency calculation of a circular plate under different boundary conditions

\begin{tabular}{lll}
\hline Boundary conditions & order & $\lambda^{2}(n)$ \\
\hline & $1^{\text {st }}$ & 10.2158 \\
\hline
\end{tabular}




\section{EXPERIMENT AND SIMULATION}

\subsection{Experiment}

The reference sample is a composite plate which consists of an aluminum alloy plate with the thickness of $2.7 \mathrm{~mm}$ and a cork plate with the thickness of $2 \mathrm{~mm}$. The length and width of the sample are $200 \mathrm{~mm}$ and $100 \mathrm{~mm}$ respectively. At the bonding interface, 4 groups of debonding defects with different sizes were created by manufacturing flat-bottom holes with 4 different diameters of $15 \mathrm{~mm}, 8 \mathrm{~mm}, 5 \mathrm{~mm}, 10 \mathrm{~mm}$ and the same depth of $0.1 \mathrm{~mm}$ in the aluminum substrate as shown in Fig.1.

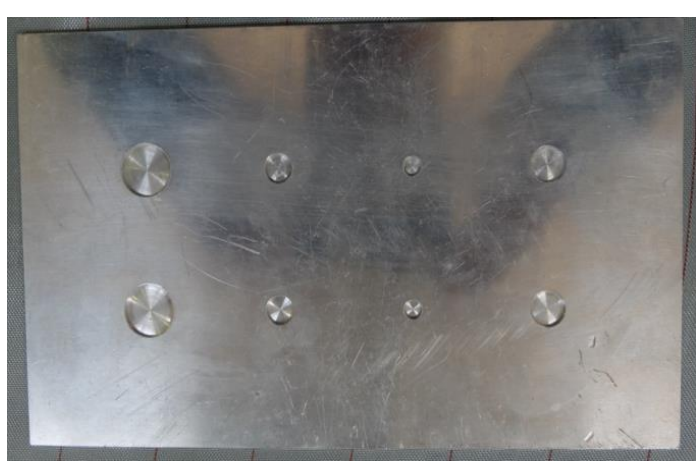

(a)

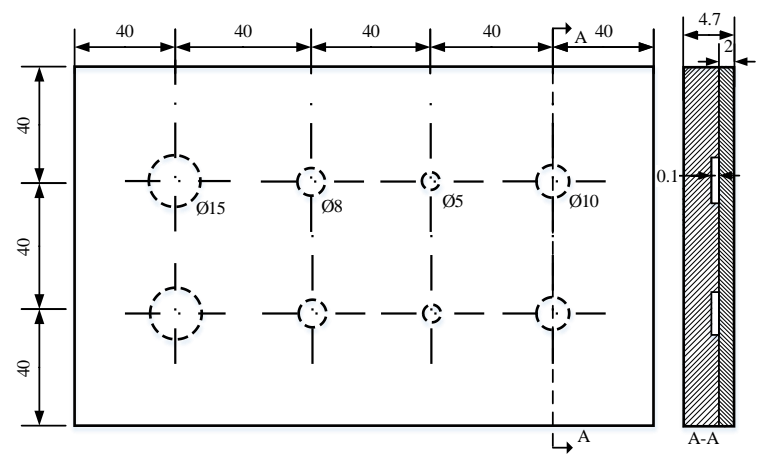

(b)

Fig.1 Photo of the aluminum substrate plate with flat-bottom holes (a) and the drawing of the composite plate (b)

In the experiment, three different types of piezoelectric transducers were adopted respectively to perform the ultrasound excitation to plate respectively. Several excitation frequencies ranging from $17 \mathrm{kHz}$ to $32 \mathrm{kHz}$ were used, while the excitation duration was set 10 seconds, and acquisition interval time is $1 \mathrm{~s}$, get 60 frames thermal image under each frequency.

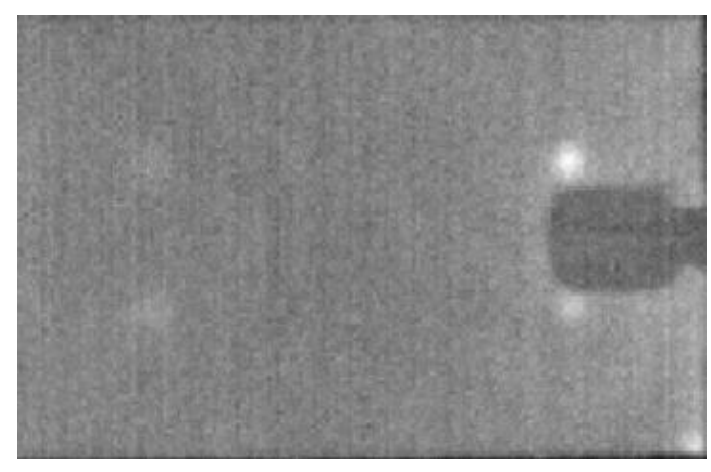

(a)

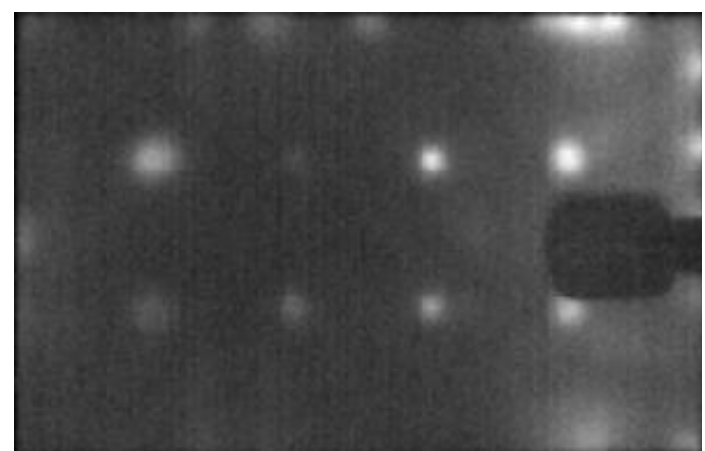

(b)

Fig. 2 Thermal images at time $\mathrm{t}=12$ under the excitation frequency of $28.7 \mathrm{kHz}$ (a) and $21.5 \mathrm{kHz}$ (b)

Because the defects on the two rows are the same, the 4 defects at the first row were selected to focus on. The temperature difference between the defect area and the non-defect area are employed to evaluate the detectability. The typical temperature difference evolutions at each defects under the excitation frequency of $21.5 \mathrm{kHz}$ are shown in Fig.3. It can be seen from Fig.4 that the temperature differences for different defect sizes have the same characters: two peaks occur at the frequency closed to $21.5 \mathrm{kHz}$ and $27 \mathrm{kHz}$. The two frequencies might be the resonance frequencies of the composite plate or the local defect resonance frequencies of the defects. 


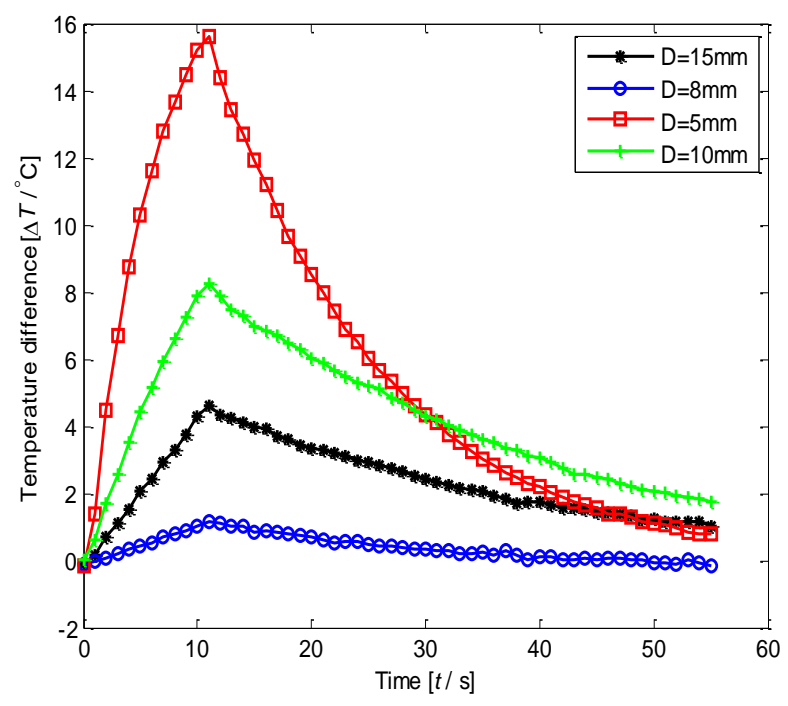

Fig.3 Temperature difference evolution at different defects under the excitation frequency of $21.5 \mathrm{kHz}$

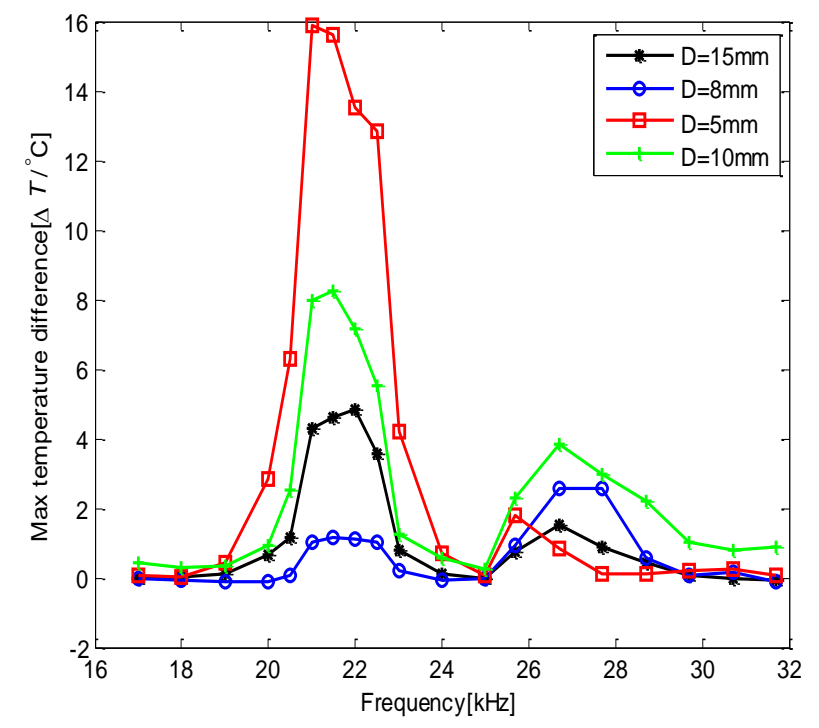

Fig.4 Experimental temperature difference vs. frequency for different defect sizes

\subsection{Simulation}

A numerical simulation model was established with the Comsol Multiphysics software. In order to verify the correctness of the modeling, the natural frequencies of the plate under different boundary conditions was calculated and the simulation results are compared to the theoretical solution given by equation (2). The finite element solution of the natural frequencies matches well with the theoretical solution as shown in Table4. Based on the suitable meshing size and boundary condition settings, further simulation such as eigenvalue analysis, a coupling analysis of vibration and thermal for the composite plates can be conducted.

Table.3 Material properties

\begin{tabular}{c|ccc}
\hline Material & Young's modulus $E(\mathrm{~Pa})$ & Poisson's ratio $\mu$ & Density $\rho\left(\mathrm{Kg} \cdot \mathrm{m}^{-3}\right)$ \\
\hline Aluminum Alloy & $7.0 \times 10^{10}$ & 0.33 & 2696 \\
Cork & $3.92 \times 10^{8}$ & 0.46 & 470 \\
\hline
\end{tabular}


Table.4 Simulation results comparing with theoretical solutions for single-layer Aluminum Alloy plate with the size $200 \mathrm{~mm} \times 120 \mathrm{~mm} \times 2.7 \mathrm{~mm}$

\begin{tabular}{|c|c|c|c|c|c|c|c|c|c|}
\hline \multirow{2}{*}{$\begin{array}{c}\text { Boundary } \\
\text { conditions }\end{array}$} & \multicolumn{3}{|c|}{ 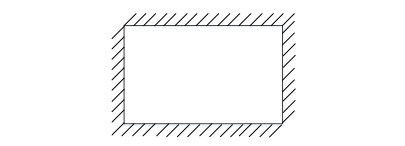 } & \multicolumn{2}{|c|}{ 弐 } & & \multirow[b]{2}{*}{$1^{\text {st }}$} & \multirow[b]{2}{*}{$2^{\text {nd }}$} & \multirow[b]{2}{*}{$3^{\text {rd }}$} \\
\hline & $1^{\text {st }}$ & $2^{\text {nd }}$ & $3^{\text {rd }}$ & $1^{\text {st }}$ & $2^{\text {nd }}$ & $3^{\text {rd }}$ & & & \\
\hline $\begin{array}{l}\text { Simulation } \\
\text { mode shape }\end{array}$ & & & & & & & & $\sigma$ & \\
\hline $\begin{array}{c}\text { frequency } \\
(\mathrm{Hz})\end{array}$ & 1209.5 & 1736.8 & 2647.0 & 57.6 & 208.3 & 357.6 & 620.7 & 1111.5 & 1932.0 \\
\hline $\begin{array}{l}\text { Theoretical } \\
\text { natural } \\
\text { frequency } \\
(\mathrm{Hz})\end{array}$ & 1208.3 & 1741.1 & 2660.2 & 58.9 & 212.0 & 369.8 & 624.2 & 1119.8 & 1945.9 \\
\hline
\end{tabular}

The comparison of the simulation results to the theoretical solutions ensures the correctness in meshing and boundary condition settings in simulation. The next work will focus on the local resonance of the circular defect areas and coupled field simulation of vibration and heat generation.

\section{CONCLUSIONS}

The expected conclusion will be that the frequency at the peak value in Fig.4 is on the frequency band of the local resonance of defect areas. The excitation at the local resonance frequency can pump more energy into the defect areas, so can improve the capability of the vibrothermography.

\section{ACKNOWLEDGMENT}

This research was supported by the National Natural Science Foundation of China (No.61571028)

\section{REFERENCES}

[1]J.B.Renshaw,J.C.Chen,et al. The Sources of Heat Generation in Vibrothermography [J]. Ndt\&E International,2011,44(8):736-739.

[2] I.Solodov, M.Rahammer, D.Derusova, G.Busse. Highly-efficient and noncontact vibro-thermography via local defect resonance [J].Quantitative Infrared Thermography Journal.2015, 12(1):1-14.

[3]I.Solodov, J.Bai, S.Bekgulyan, G.Busse. A local defect resonance to enhance acoustic wave-defect interaction in ultrasonic nondestructive evaluation [J]. Applied Physics Letters, 2011, 99(21):211911(1-4).

[4]Arthur W.Leissa. VIBRATION OF PLATES [M]. Ohio State University, 1969, 1-52. 